\title{
Alteration in the Expression of Alzheimer's-Related Genes in Rat Hippocampus by Exercise and Morphine Treatments
}

\author{
Hosseinali Sasan ${ }^{*}$, Azadeh Samareh Gholami ${ }^{1}$, Mohammad Hashemabadi ${ }^{1,2}$ \\ ${ }^{1}$ Department of Biology, Faculty of Sciences, Shahid Bahonar University of Kerman, Kerman, Iran \\ ${ }^{2}$ Department of Genetic, Faculty of Biological Sciences, Tarbiat Modares University, Tehran, Iran
}

\section{Article Info:}

Received: 6 May 2019

Revised: 13 Jul 2019

Accepted: 22 Aug 2019

\section{ABSTRACT}

Introduction: Alzheimer's disease is a progressive brain disorder, which slowly eliminates memory and intellectual ability and eventually destroys the ability to carry out the simple tasks. $\beta$ amyloid plaque and neurofibrillary tangles are two important signatures of this disease, which caused by mutant in Tau, BACE1, and APP genes. They could be important targets for treatment of Alzheimer's disease. Materials and Methods: Twenty-eight adult male Wistar rats weighing 180-240 g were classified into four groups, including control, morphine treatment, exercise treatment, and both morphine and exercise groups. After RNA extraction from hippocampal tissues and cDNA synthesis, Real time PCR for evaluation of different expressions of BACE1 and APP genes were performed. Results: Data revealed that the expressions of BACE1 and APP significantly decreased during morphine and exercise treatment. Conclusion: The present study suggests the possible role of morphine and exercise in treatment of Alzheimer's disease, possibly due to down-regulation of BACE1 and APP.

*Corresponding Author: Hosseinali Sasan

E-mail: hsasa@uk.ac.ir 


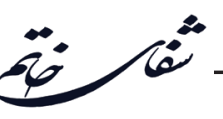

تغيير در بيان زنهاى مرتبط با آلزايمر در هييوكامٍ موشهاى صحرايى توسط درمان با مورفين و تمرين ورزشى

\author{
حسينعلى ساسان"'، آزاده ثمره غلامى'، محمد هاشم آبادى ‘، \\ 'كروه زيست شناسى، دانشكده علوم، دانشكاه شهيد باهنر كرمان، كرمان، ايران \\ "َّروه زنتيك، دانشكده علوم زيستى، دانشكاه تربيت مدرس، تهران، ايران
}

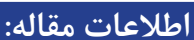

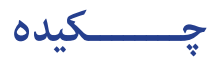

مقدمه: بيمارى آلزايمر يك اختلال مغزى ييشرونده است كه به آرامى حافظه و قدرت تفكر را از بين برده

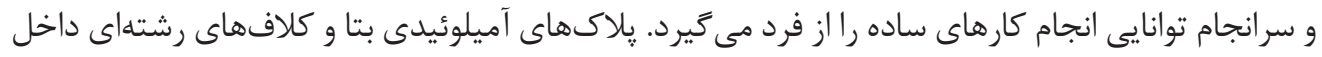

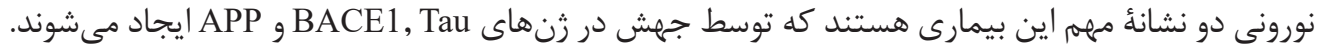

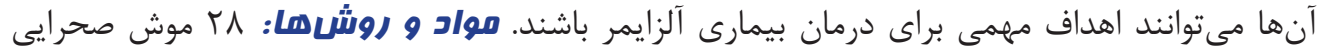

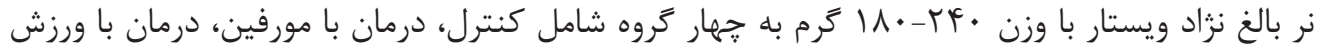

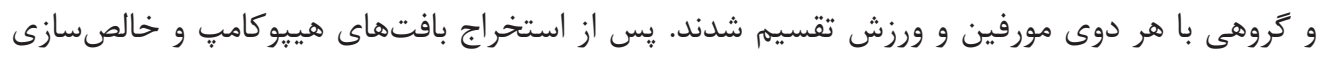

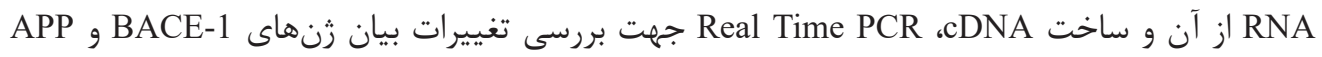

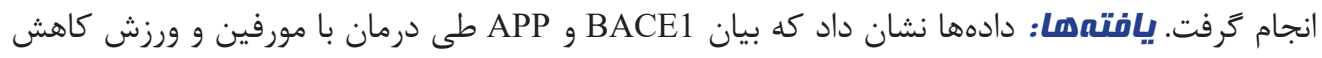

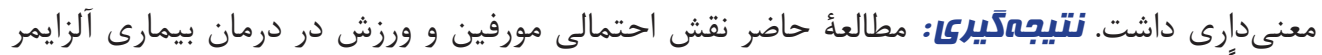

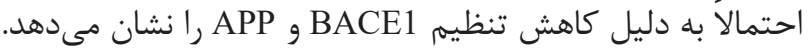

\footnotetext{
: : : : كليد وازهها:

ا. بيمارى آلزايمر r:

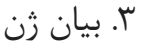

أ.

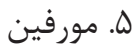

* نويسنده مسئول: حسينعلى ساسان

آدرس الكترونيكى: hsasa@uk.ac.ir 


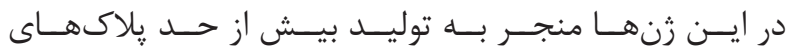

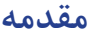

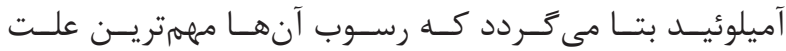

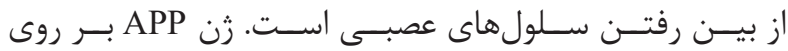

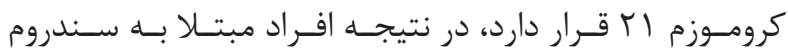

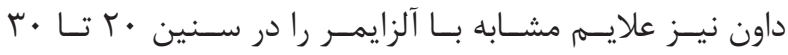

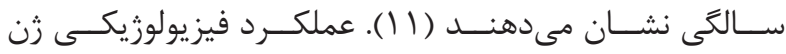

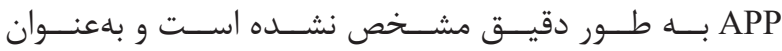

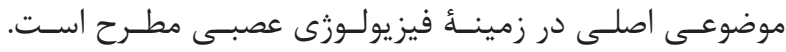

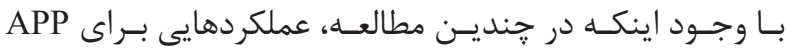

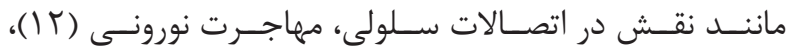

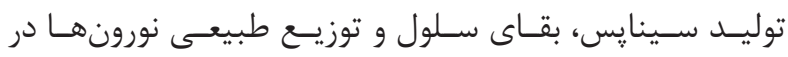

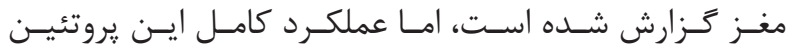

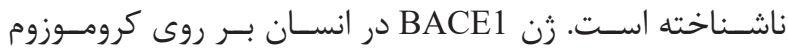

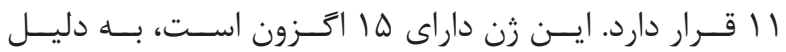

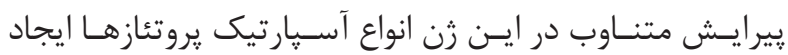

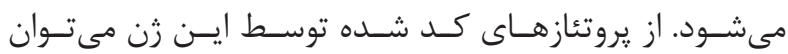

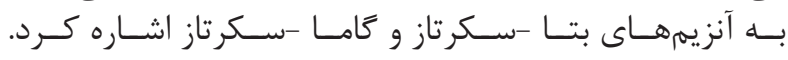

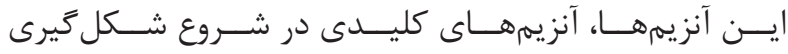

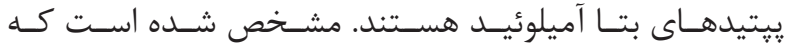

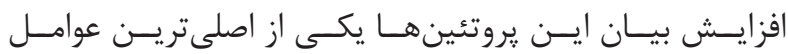

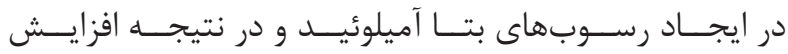

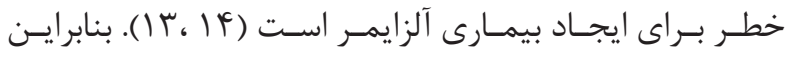

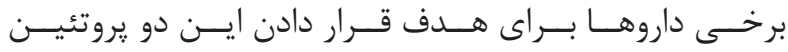

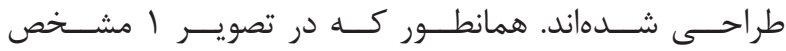

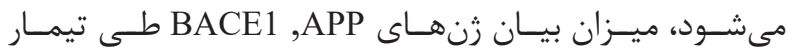

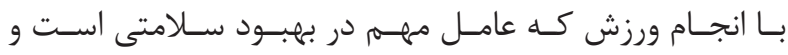

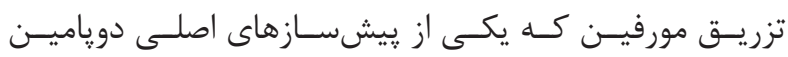

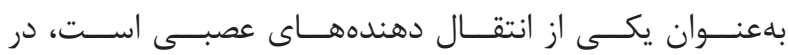

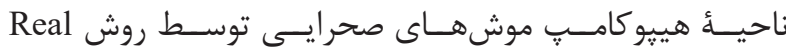

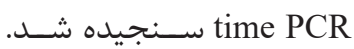

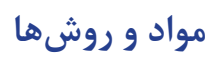

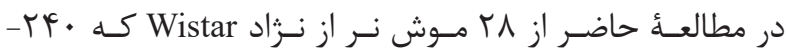

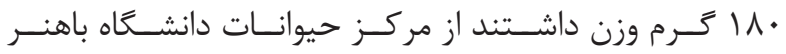

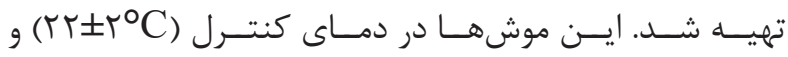

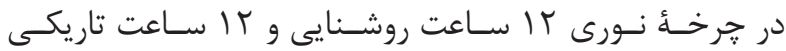

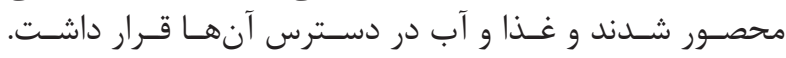

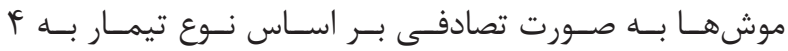

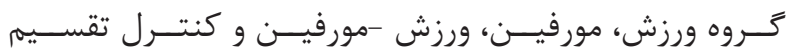

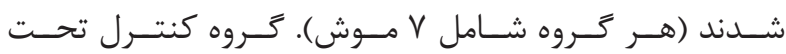

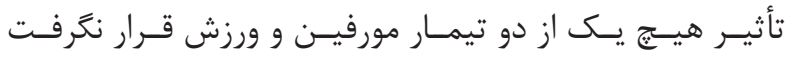

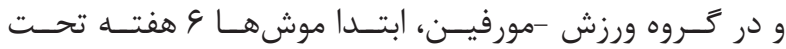

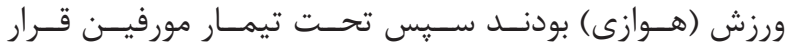

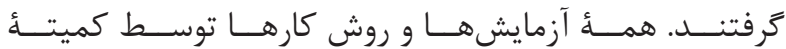

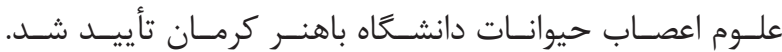

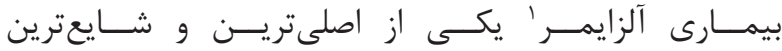

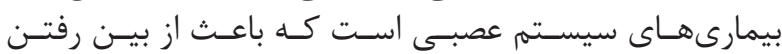

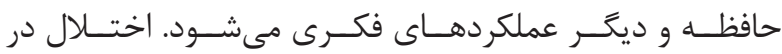

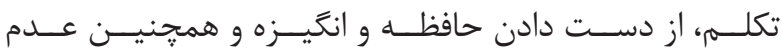

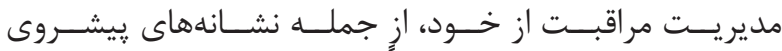

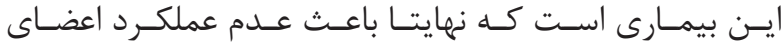

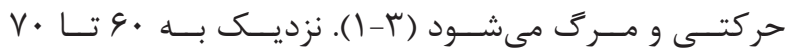

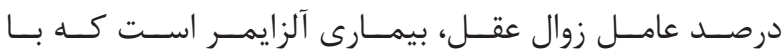

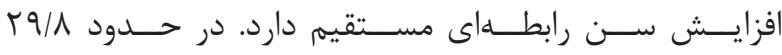

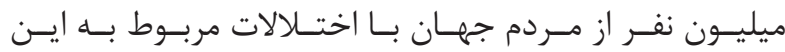

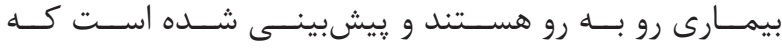

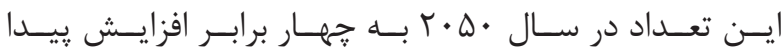

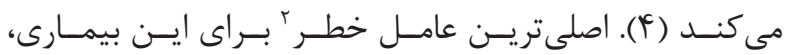

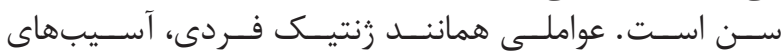

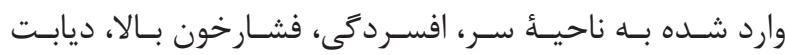

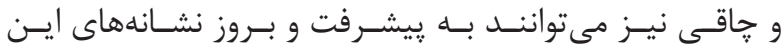

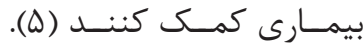

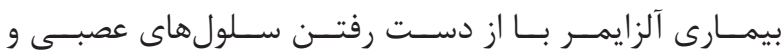

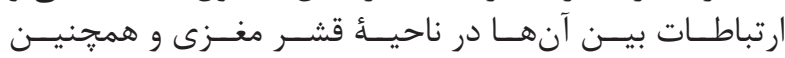

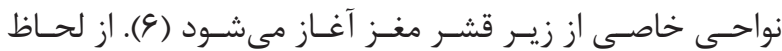

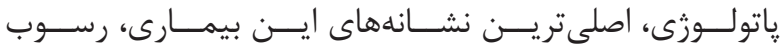

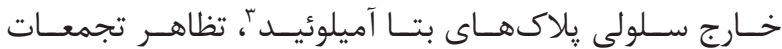

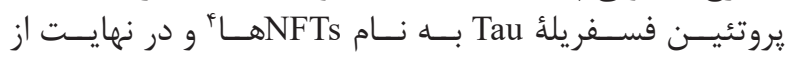

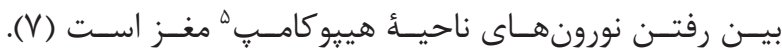

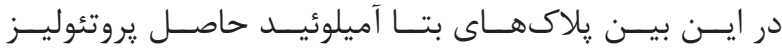

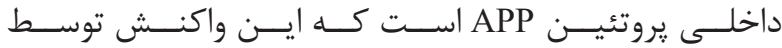

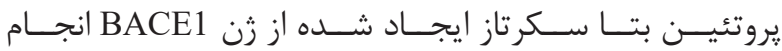

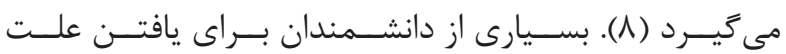

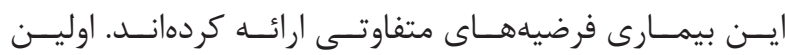

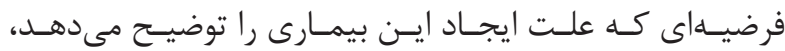

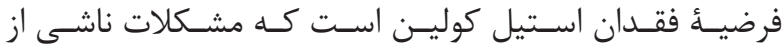

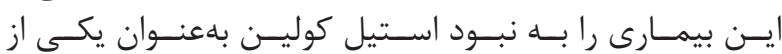

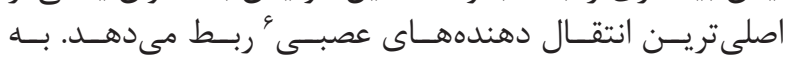

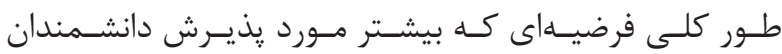

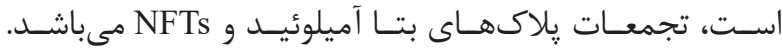

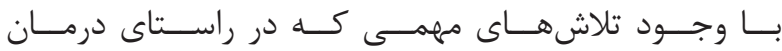

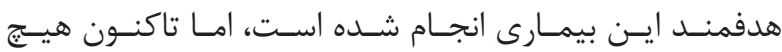

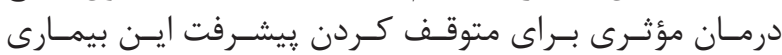

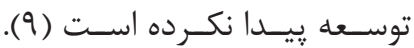

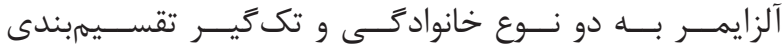

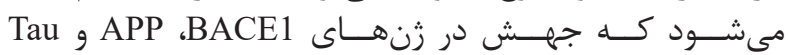

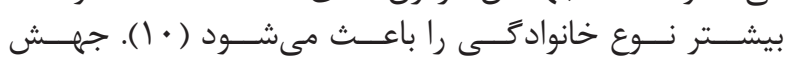




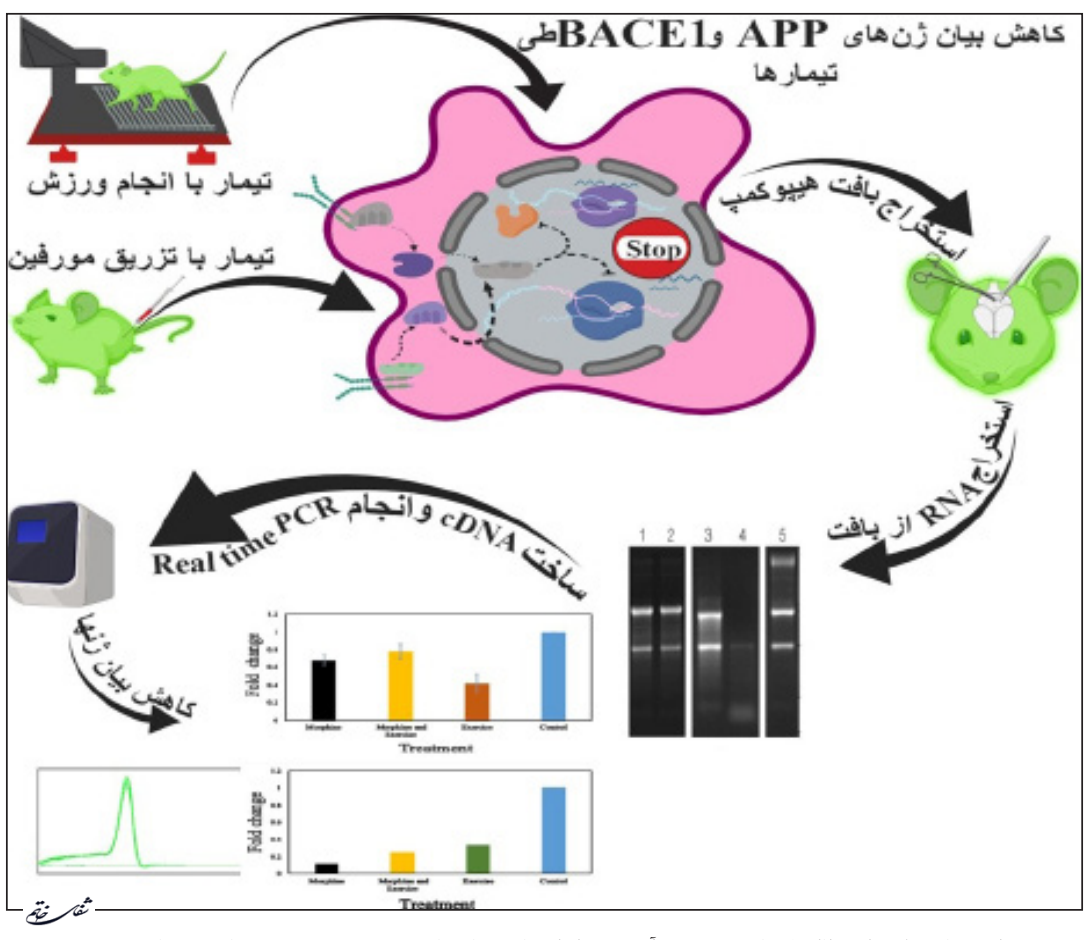

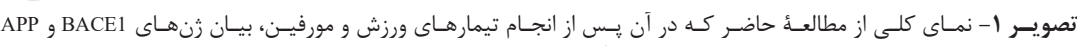

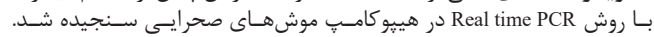

اسـتخراج كرديــد. بــراى بررسـى كيفيـت و كميـت RNA

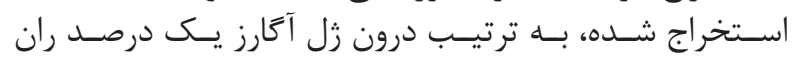

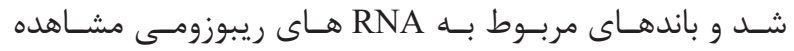

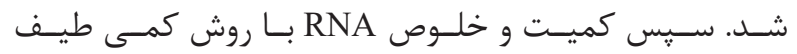

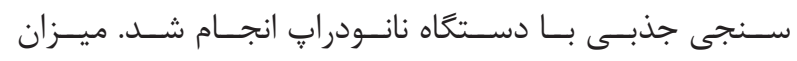

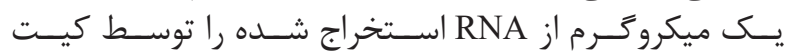
Thermo شـ RevertAid First Strand cDNA Synthesis

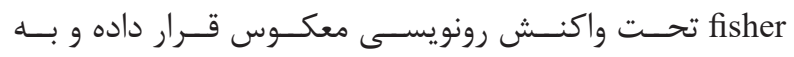

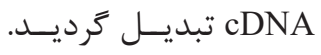

Real time PCR واكنش

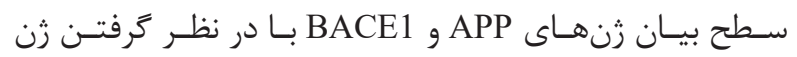

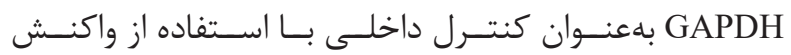
Real time PCR

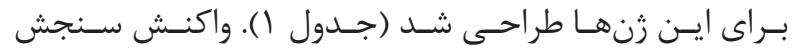

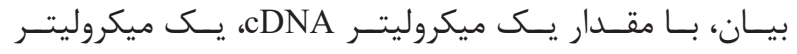

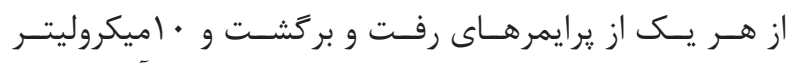

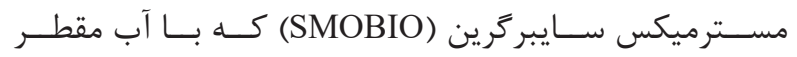

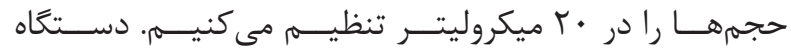
Analytical gena

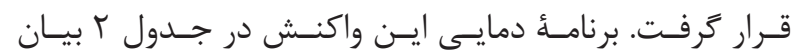

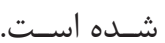

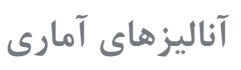

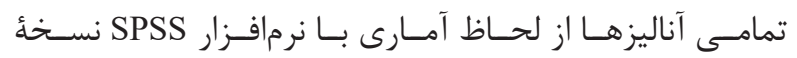

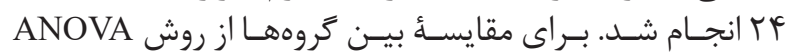

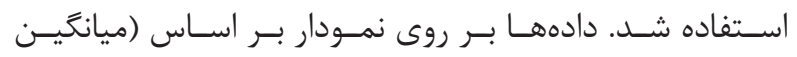

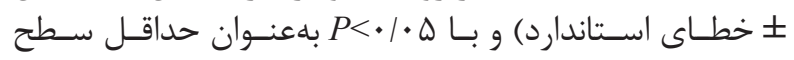

دستور العمل انجام ورزش هوازى

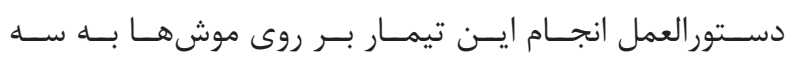

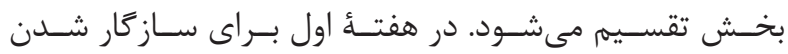

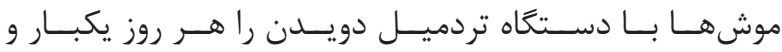

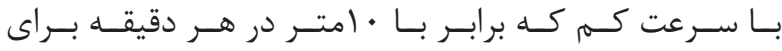

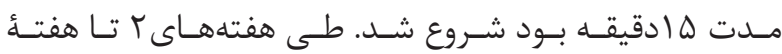

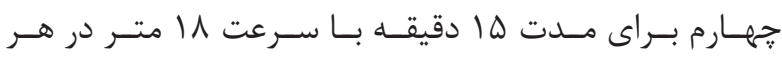

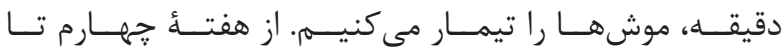

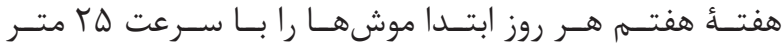

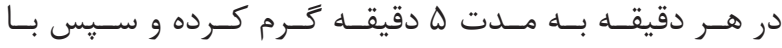

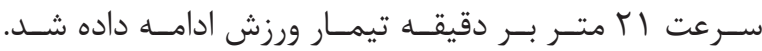

$$
\text { دستور العمل تزريق مورفين }
$$

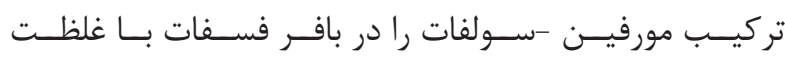

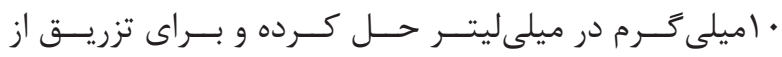

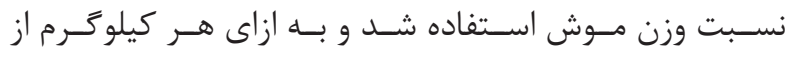

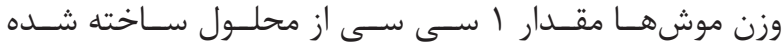

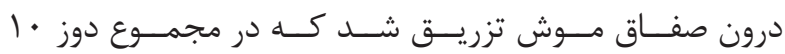

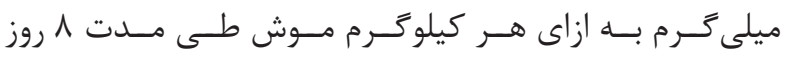

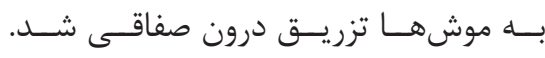

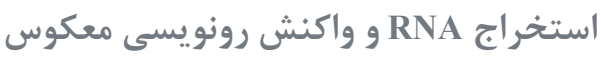

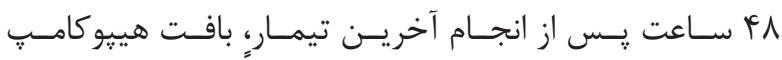

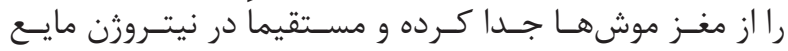

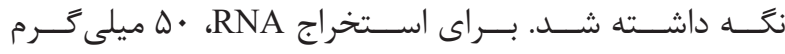

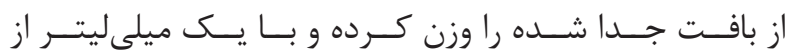

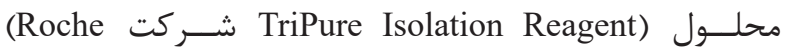
آن را همخــن كـرده و بــا دســتورالعمل كيـت، RNA RN بافـت 
جدول ا- توالى يرايمرهاى اختصاصى براى انجام آزمايش Real time PCR.

\begin{tabular}{|c|c|c|c|}
\hline نام برايمر & توالى برايمرهاى اختصاصى براى ثرن ها & طول محصول (bp) & دماى اتصال برايعرها ('C) \\
\hline APRF & 5-GCAGAATGGAAAATGGGAGTCAG & \multirow{2}{*}{199} & \multirow{2}{*}{$\Delta \varphi$} \\
\hline APRR & 5-AATCACGATGTGGGTGTGCGTC & & \\
\hline BACRF & 5- AATCAGTCCTTCCGCATCAC & \multirow{2}{*}{ iv. } & \multirow{2}{*}{$\Delta Q / \Delta$} \\
\hline BACRR & 5-ATGTGGTCTTTGATCGAGCC & & \\
\hline GAPRF & 5-GCGAGATCCCGCTAACATCA & \multirow{2}{*}{ ive } & \multirow{2}{*}{$\Delta V$} \\
\hline GAPRR & 5-CTCGTGGTTCACACCCATCA & & \\
\hline
\end{tabular}

草

جدول r- برنامة دمايى براى انجام واكنش Real Time PCR.

\begin{tabular}{|c|c|c|c|}
\hline مرحله & Los & زمان (دقيقه) & تعداد سيكل \\
\hline واسرشتخىى اوليد & $9 \Delta\left({ }^{\circ} \mathrm{C}\right)$ & • 1 دقيقد & 1 \\
\hline واسرشتخى & $9 \Delta\left({ }^{\circ} \mathrm{C}\right)$ & ك ثانيه & \multirow{3}{*}{ ro } \\
\hline 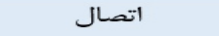 & $\Delta S-\varphi+\left({ }^{\circ} \mathrm{C}\right)$ & ل ب ثانيد & \\
\hline طويل شسن & $\mathrm{R}\left(\mathrm{O}^{\circ} \mathrm{C}\right)$ & • ب ثانيد & \\
\hline طويل شدن نهيايى & $V+\left({ }^{\circ} \mathrm{C}\right)$ & ه دقيقه & 1 \\
\hline
\end{tabular}

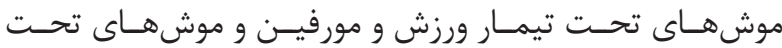

معنـى دارى نمايسش داده شـد.

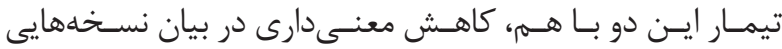

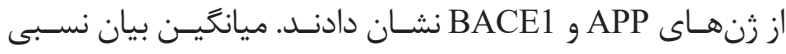

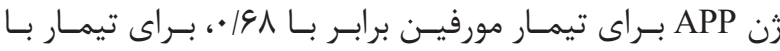

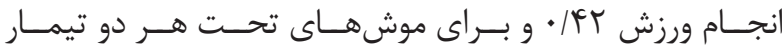

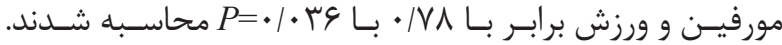

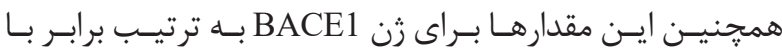

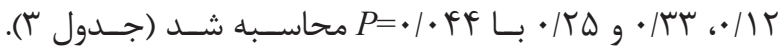

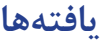
بيـان نسـبى زنهــاى BACE1 و APP در ناحيـهُ هييو كامست

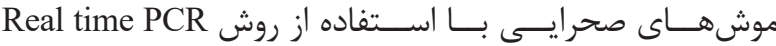

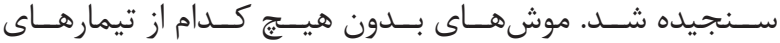

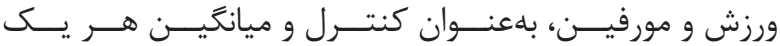

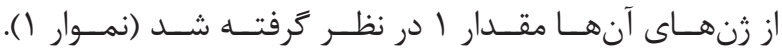
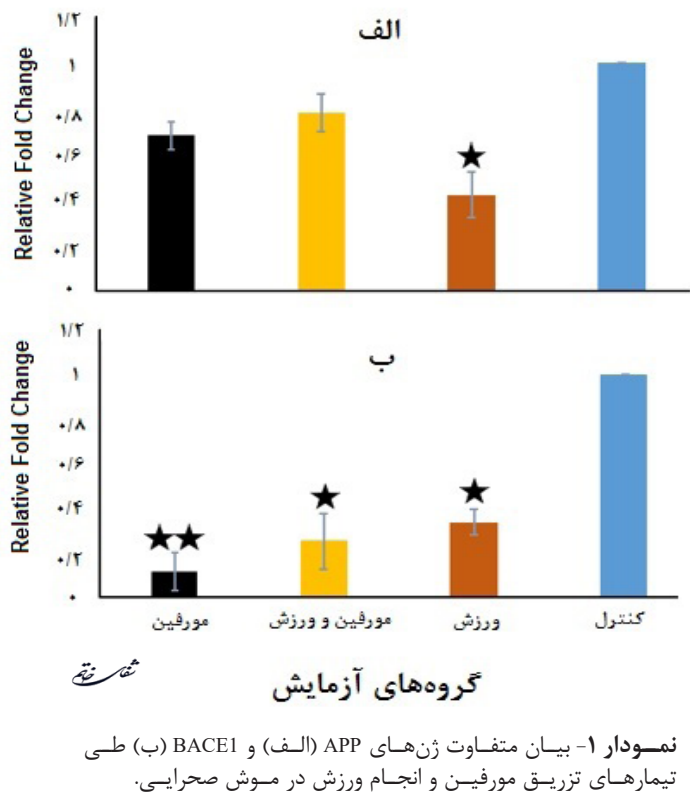

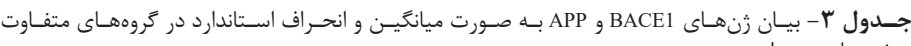
موشهــاي صحرايسى. بـ

\begin{tabular}{|c|c|c|}
\hline تيمار & مياتخين يبان رثن & ميانغين بيان رن \\
\hline مورفين & $\cdot / \cdot 9 \pm \cdot / 1 r$ & $\cdot / \cdot \Delta Q \pm \cdot / 8 \wedge$ \\
\hline ورزش & מس/• I. & $\cdot / \cdot 9 \pm \cdot / 4 t$ \\
\hline مورفين -ورزث & $\cdot / 1 r \pm \cdot / r \Delta$ & 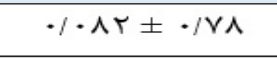 \\
\hline
\end{tabular}




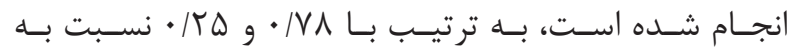

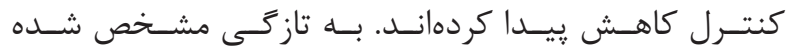

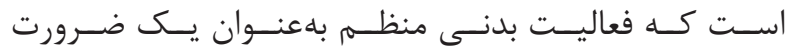

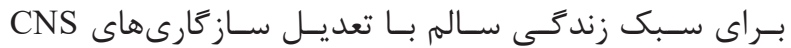

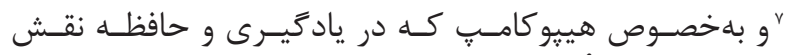

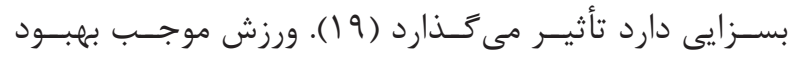

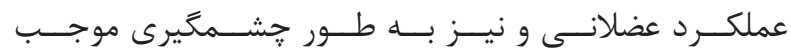

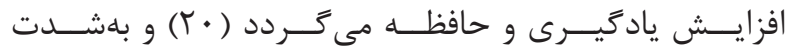

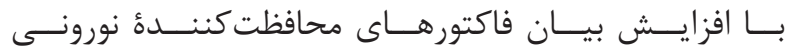

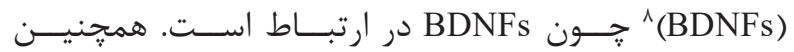

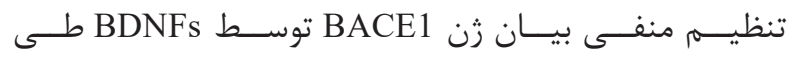

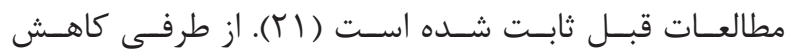

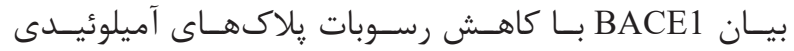

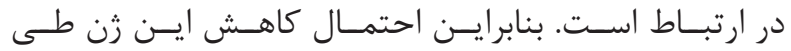

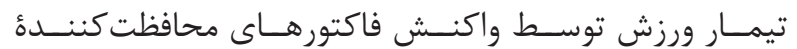

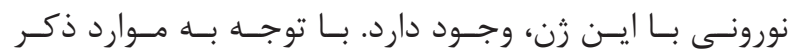

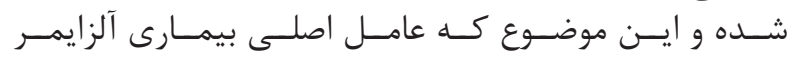

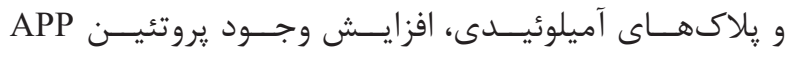

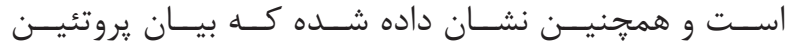

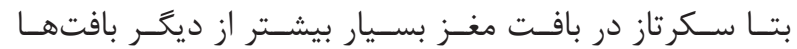

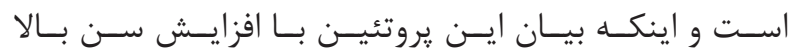

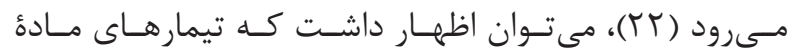

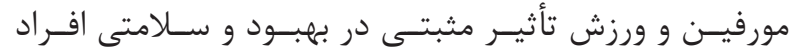

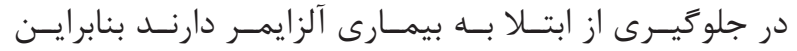

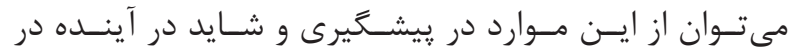

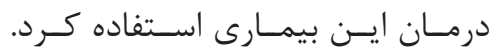

1. Peric A, Annaert W. Early etiology of Alzheimer's disease: tipping the balance toward autophagy or endosomal dysfunction? Acta Neuropathol. 2015; 129(3): 363-81.

2. Dal Forno G, Palermo MT, Donohue JE, Karagiozis $\mathrm{H}$, Zonderman AB, Kawas CH. Depressive symptoms, sex, and risk for Alzheimer's disease. Ann Neurol. 2005; 57(3): 381-7.

3. Risacher SL, Saykin AJ. Neuroimaging and other biomarkers for Alzheimer's disease: the changing landscape of early detection. Annu Rev Clin Psychol. 2013; 9: 621-48.

4. Reitz C, Mayeux R. Alzheimer disease: epidemiology, diagnostic criteria, risk factors and biomarkers. Biochem Pharmacol. 2014; 88(4): 640-51.

5. Vinters HV. Emerging concepts in Alzheimer's
بحث و نتيجه كيرى

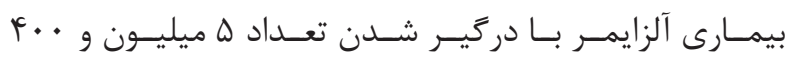

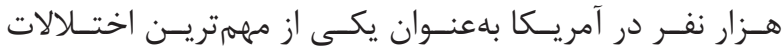

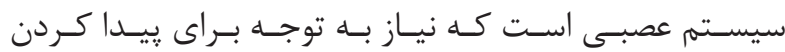

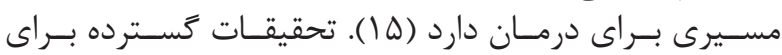

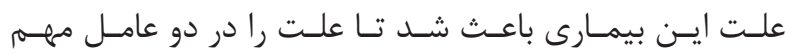

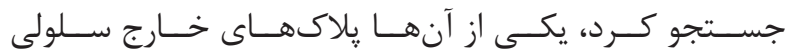

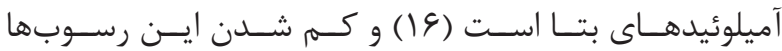

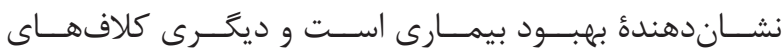

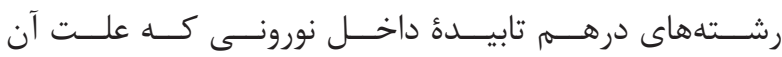

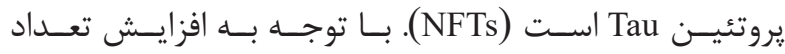

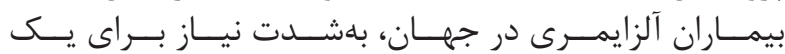

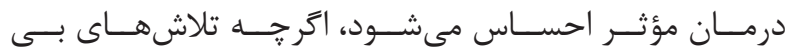

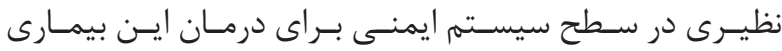

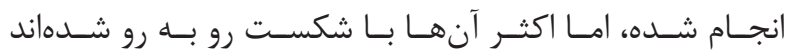

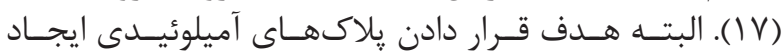

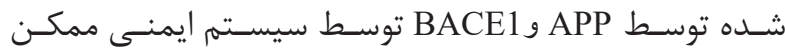

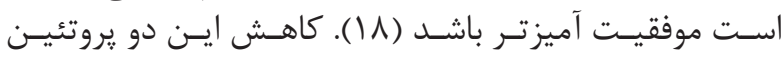

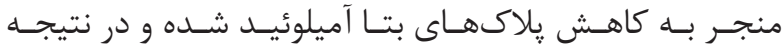

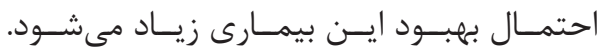

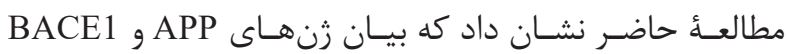

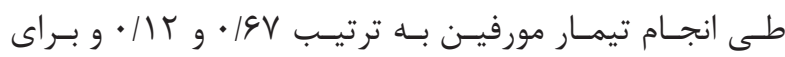

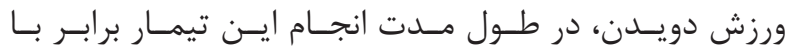

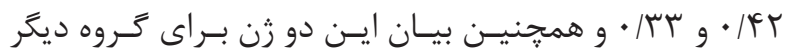

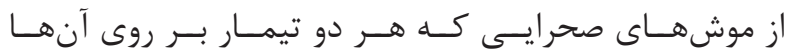

منابع

disease. Annual Review of Pathology. Mechanisms of Disease. 2015; 10: 291-319.

6. Khachaturian ZS. Diagnosis of Alzheimer's disease. Archives of Neurology. 1985; 42(11): 1097-105.

7. Selkoe DJ. Alzheimer's disease: genes, proteins, and therapy. Physiol Rev. 2001; 81(2): 741-66.

8.Sun X, He G, Qing H, Zhou W, Dobie F, Cai F, et al. Hypoxia facilitates Alzheimer's disease pathogenesis by up-regulating BACE1 gene expression. Proc Natl Acad Sci U S A. 2006; 103(49): 18727-32.

9. Selkoe DJ. Alzheimer's disease is a synaptic failure. Science. 2002; 298(5594): 789-91.

10. Rossor M, Fox N, Freeborough P, Harvey R. Clinical features of sporadic and familial Alzheimer's disease. Neurodegeneration. 1996; 5(4): 393-7.

\footnotetext{
${ }^{7}$ Central nervous system

${ }^{8}$ Brain-derived neurotrophic factors
} 
11. Dorostkar MM, Zou C, Blazquez-Llorca L, Herms J. Analyzing dendritic spine pathology in Alzheimer's disease: problems and opportunities. Acta Neuropathol. 2015; 130(1): 1-19.

12. Manocha GD, Floden AM, Rausch K, Kulas JA, McGregor BA, Rojanathammanee L, et al. APP regulates microglial phenotype in a mouse model of Alzheimer's disease. J Neurosci. 2016; 36(32): 8471-86.

13. Niwa K, Kazama K, Younkin SG, Carlson GA, Iadecola C. Alterations in cerebral blood flow and glucose utilization in mice overexpressing the amyloid precursor protein. Neurobiol Dis. 2002; 9(1): 61-8.

14. Cheon M, Dierssen M, Kim S, Lubec G. Protein expression of BACE1, BACE2 and APP in Down syndrome brains. Amino Acids. 2008; 35(2): 339-43.

15. Association As. 2016 Alzheimer's disease facts and figures. Alzheimers Dement. 2016; 12(4): 459-509.

16. Duce JA, Bush AI. Biological metals and Alzheimer's disease: implications for therapeutics and diagnostics. Prog Neurobiol. 2010; 92(1): 1-18.
17. Salloway S, Sperling R, Fox NC, Blennow K, Klunk W, Raskind M, et al. Two phase 3 trials of bapineuzumab in mild-to-moderate Alzheimer's disease. N Engl J Med. 2014; 370(4): 322-33.

18. Sevigny J, Chiao P, Bussière T, Weinreb PH, Williams $\mathrm{L}$, Maier $\mathrm{M}$, et al. The antibody aducanumab reduces $\mathrm{A} \beta$ plaques in Alzheimer's disease. Nature. 2016; 537(7618): 50-6.

19. Kosten TR, George TP. The neurobiology of opioid dependence: implications for treatment. Sci Pract Perspect. 2002; 1(1): 13-20.

20. Sutoo De, Akiyama K. Regulation of brain function by exercise. Neurobiol Dis. 2003; 13(1): 1-14.

21. Devi L, Ohno M. 7, 8-dihydroxyflavone, a smallmolecule TrkB agonist, reverses memory deficits and BACE1 elevation in a mouse model of Alzheimer's disease. Neuropsychopharmacology. 2012; 37(2): 434-44.

22. Vassar R, Kandalepas PC. The $\beta$-secretase enzyme BACE1 as a therapeutic target for Alzheimer's disease. Alzheimers Res Ther. 2011; 3(3): 20. doi: 10.1186/ alzrt82. 